\title{
La construcción del paisaje mexicano en la revista MAPA, 1934-1940'
}

\author{
Héctor Mendoza Vargas²
}

\begin{abstract}
RESUMEN
Tema central de la geografía cultural, el paisaje se ha integrado a las opciones desde las cuales se estudian las identidades nacionales en América Latina. Este artículo indaga cómo un proyecto intelectual y editorial, la revista MAPA, abrió sus páginas en los años 1930 a la construcción y definición de los paisajes mexicanos, lo que brindaba un sentido de identidad a la vida individual. Esta publicación aplicaba una visión alternativa ante el auge de una educación socialista bajo el impulso del Estado. Se eligieron tres secciones: los "Caminos", el "Automovilismo" y "Viajes y excursiones" para identificar los elementos de la organización moderna de los viajes y determinar las nuevas prácticas culturales para el conocimiento del territorio, relacionadas con las nuevas carreteras y la difusión social del automóvil. En el periodo elegido, el paisaje cambiaba rápidamente y ocupaba un sitio importante dentro de la construcción de la identidad nacional.
\end{abstract}

Palabras clave: Paisaje mexicano, viaje, carreteras, automóvil, revista ilustrada

\begin{abstract}
As a central theme in cultural geography, landscape has been incorporated as one of the ways through which to study national identities in Latin America. This article discusses how an intellectual and editorial project, MAPA magazine, opened its pages to the observation and definition of Mexican landscapes in 1930, providing a sense of individual identity. This publication applied an alternative vision before the rise of a state-sponsored socialist education. Three sections were chosen: "Roads," "Auto" and "Trips and tours," to identify the organizational elements of modern leisure travel and to determine the emerging cultural practices of geographical knowledge, related to the new network of roads and the social dissemination of the automobile. In the period under study, the landscape was changing fast and occupied an important place in the construction of national identity.
\end{abstract}

Key words: Mexican landscape, leisure travel, roads, automobile, illustrated magazine.

Este trabajo se elaboró en el marco del PAPIIT proyecto IN301316, 2016-2017, de la Dirección General de Asuntos del Personal Académico de la UNAM. El autor agradece a Atlántida Coll, a Federico Fernández Christlieb y a los lectores de la revista por los comentarios sugeridos al trabajo. Artículo recibido el 5 de noviembre de 2015, aceptado el 28 de enero de 2016 y corregido el 5 de octubre de 2016.

Instituto de Geografía, Universidad Nacional Autónoma de México (México). E-mail: hvargas@unam.mx 
MAPA abría sus páginas poco antes de la elección de Lázaro Cárdenas como Presidente de México (1934-1940), quien buscó una estabilidad política con el apoyo de las masas obreras y campesinas y dio prioridad a la renovación económica a favor de los comerciantes, agricultores y mineros (González, 1981: 14). En esta dirección, algunos proyectos cobraron un perfil nacional, como la construcción de carreteras bajo un modelo de "morfología radial con centro en la ciudad de México" (González, 1990: 57). Las nuevas carreteras, a cargo de la Comisión Nacional de Caminos, convirtieron el país no nada más en un entrecruzamiento vial, a partir de 1925, sino que representaron una nueva modalidad del viaje y la creación de una "cultura territorial de una sociedad" (Martínez de Pisón, 2009: 68). Con el kilometraje construido por el gobierno se abrieron nuevas relaciones con el espacio y una nueva movilidad que situaba a México entre las preferencias de los viajeros tanto nacionales como extranjeros (Boardman, 2001; Berger, 2006).

Una variedad de rasgos geográficos, promocionados desde los años veinte del siglo pasado, combinaron las vistas panorámicas con los sabores y olores mexicanos; las pirámides, las montañas, los manantiales, el clima y las playas (Libro, 1923: v). Todo esto suscitaba entre los viajeros un placer visual y la confección de una nueva cultura sobre los paisajes. Tal variedad se basaba en la promoción de una serie de contenidos culturales que integraban el paisaje. Abierto el campo visual y el tono anímico del observador. ¿cómo se propiciaba la interiorización de los rasgos geográficos y la construcción de lo nacional a través del paisaje? Los medios impresos eran una producción cultural que transformaban la experiencia vivida del público y, a la vez, modificaban las percepciones individuales y prolongaban el recuerdo del viaje (Quintana, 2009: 239).

El paisaje ha representado uno de los temas centrales de la geografía cultural (Claval, 1999 y 2002; Cosgrove, 1988 y 2002; Fernández, 2006; Maderuelo, 2006 y 2009; Nogué, 2008; Domingues, 2001; Ortega, 2006; Tesser, 2000; Salter, 1994) y comprende tanto las configuraciones naturales como los productos históricos, es decir "sus formas documentan hoy el peso de nuestra cultura sobre su espacio como archivos a escala territorial" (Martínez de Pisón, 2009: 63). A una morfología con condiciones y relaciones geográficas, "se añade un legado de percepción y representación. Por ello, sin mirada cultural no hay imagen, sentidos ni valores, no hay paisaje en el territorio" (Martínez de Pisón, 2009: 48). Por eso, el paisaje se ha integrado a las opciones con que se estudian las identidades nacionales en América Latina (Piglia, 2014; Silvestri, 2011; Booth, 2008). En estos contextos, este artículo se interesa por saber cómo las expresiones gráficas guiaron las miradas hacia las "formas de ver, maneras de vivir y de comprender la vida nacional" (Dorotinsky, 2008: 10). Una nueva cultura visual, centrada en el paisaje mexicano, era difundida por medio de los escritos y las imágenes, con lo que consiguieron la conexión del paisaje con la mirada (Cosgrove, 2002: 64), particularmente, de los viajeros no especializados a través de libros, revistas, folletos, carteles, mapas o tarjetas postales (Albiñana, 2014; Arriola, 2013; Uribe, 2011).

Una de las publicaciones que dirigieron sus intereses hacia el paisaje mexicano era la revista MAPA, fundada por Francisco Borja Bolado, un periodista que en sus viajes conoció los paisajes de Colombia, Argentina y Chile. Ahí las guías y revistas eran parte de una cultura que demandaba información espacial, por lo que ocuparon un lugar modernizador en la sociedad (Errázuriz, 2016; Piglia, 2014; Booth, 2008). Una experiencia que amplió, entre 1923 y 1927, como vicecónsul de México en Boston y luego en Hamburgo, Alemania. Los contactos se ampliaron con su labor en la política mexicana como jefe de prensa de la Secretaría de Hacienda, al mismo tiempo que dirigió el diario El Economista, entre 1927 y 1932, por lo que su figura se encontraba bien posicionada 
para emprender un nuevo proyecto editorial que, a la vez, coincidía con la promoción del nacionalismo cultural que interesaba al gobierno federal (López, 2010: 145; Jolly, 2014).

Los primeros años de la revista, de 1934 a 1940, quedaron enmarcados, por un lado, por el nuevo trazo que representaron las carreteras: la de Nuevo Laredo en 1936 y la de Guadalajara en 1939 y, por el otro, la reacción de la revista ante la apertura de estos escenarios y la promoción que asume de una cultura del viaje, la relación abierta y acelerada por el coche entre el viajero y el paisaje mexicano. La mirada de los lectores será educada en lo espacial y se indicaron en las páginas tanto las antiguas modalidades del viaje en ferrocarril o en barco, como la del avión. La revista MAPA ordenaba y actualizaba la información sobre los lugares y sobre la manera de viajar con base en las fotografías, las instrucciones y los mapas. Las páginas de la revista formaban una especie de álbum geográfico con una variedad de opciones señaladas a los particulares, en consonancia con la motorización de la vida privada y el impulso nacionalista del gobierno. El nombre de la revista MAPA, en mayúsculas en toda la formación, aludió a este artefacto cultural que, en ese momento, se insertaba en un ambiente editorial e intelectual emergente por lo que el mapa, junto con la fotografía, potenciaba la visualidad abierta por este proyecto editorial. MAPA formaba un novedoso dispositivo impreso de comunicación que llevaba, al interior de la cultura mexicana, el paisaje con lo que contribuyó de "distintas maneras a construirlo" (Minca, 2008: 223).

Ante la pregunta, ¿cómo la revista MAPA orientaba, entre los viajeros, la construcción de una visión sobre el paisaje a mediados del siglo XX?, este artículo abordará la contemplación o el acto de ver el paisaje no como un proceso mecánico-fisiológico, sino como una "nueva manera de decir lo que se ve" (Hernández, 2016: 11). Se explorará, en la primera parte, el surgimiento de una nueva producción cultural, la revista MAPA, que se propuso dar a conocer el país al viajero, era un nuevo personaje, al que enseñaba qué ver, con lo que modificaba los gustos, hábitos y relaciones con el ambiente (Maderuelo, 2006: 7). En particular se refiere a cómo un proyecto intelectual y editorial, la revista MAPA, abrió sus páginas en los años treinta, tanto a lo natural como a lo humano de los paisajes. Por esto, se revisará la revista MAPA como un producto promotor de un tipo de cultura relacionada con un "largo y articulado proceso de construcción" (Aime, 2015: 31)3.

Abierto este planteamiento, enseguida se indagará la participación de esta empresa privada y cómo la revista MAPA buscaba convertirse en un referente del orden espacial que construye lo mexicano. Para esto, se verá el lugar de las carreteras y los automóviles que respaldaron el viaje como una nueva práctica cultural. La revista asume un nuevo estilo de vida y presentaba los lugares con la combinación de la historia, la fotografía y los mapas que cumplieron una función novedosa para la difusión de una cultura del viaje, del paisaje y de las nuevas relaciones abiertas entre el viajero, el camino y el orden de los espacios mexicanos llevado a la revista. Al mismo tiempo, un conjunto de emociones y sentimientos entre los viajeros propiciaba un sentido de identidad o pertenencia.

Lo que se entiende por cultura ha cambiado sustancialmente, en los últimos años, de las visiones rígidas a otras más flexibles o fluidas. Marco Aime indica que es "a partir del diálogo, del intercambio, del encuentro que nace cada cultura" (Aime, 2015: 31). En las culturas hay un proceso de comunicación y comportamientos compartidos y, a la vez, "son instrumentos que le sirven a los hombres para ordenar a su manera el mundo que los rodea, para recolocar, según sus parámetros, lo que aparentemente no tiene un orden o, mejor dicho, lo que no tiene un orden "humano." (Aime, 2015: 32). 
En este marco, para este artículo se han elegido tres secciones de la revista donde se identifican los elementos modernos de la organización de los viajes, entendidos como las nuevas prácticas de movilidad que surgen en la sociedad mexicana. Con este objeto, se han seleccionado los apartados de los "Caminos", el "Automovilismo" y el de "Viajes y excursiones" de esta revista, entregada mensualmente para ofrecer, entre los lectores, una visión del paisaje. Tal espacio editorial surge entre una visión mecanizada a través de la fotografía y los rápidos cambios del paisaje mexicano dentro de un contexto político específico, iniciado en 1934, así como por la plena identificación del proyecto con los espacios vividos y los rasgos geográficos en la construcción del paisaje.

\section{Una nueva producción cultural mexicana: la revista MAPA}

El proyecto de la revista MAPA surgió de forma paralela a otras prácticas similares que situaban un proceso de cambio editorial. El editor italiano José Anesi (1881-1963), desde Buenos Aires dio a conocer la "Revista Geográfica Americana", a partir de octubre de 1933, para la promoción del gusto por los viajes y la invención de los paisajes nacionales, como parte de las actividades modernizadoras y educativas (Zusman, 2012: 82). A su publicación mensual, se ha reconocido, le dio un "aire de familia" con la "National Geographic Magazine"4. La influencia de esta revista, editada en Washington, D. C., desde 1888, ha sido ampliamente identificada, entre los lectores de los Estados Unidos, en la "forma de percibir el mundo, sus culturas y sus paisajes" (García, 2013: 1). En este ámbito editorial, se sitúa la revista chilena "En Viaje", que contaba con la colaboración del fotógrafo suizo Roberto Montandon Paillard (1919-2003) para despertar la curiosidad por el "paisaje natural, el sol, el terral del páramo, los oasis y las construcciones de culturas prehispánicas" del norte de Chile (González, 2013: 228). Estos impulsos dejaban constancia de los diversos emprendimientos en varias ciudades latinoamericanas para la creación de nuevas agendas editoriales donde la "letra y la imagen adquirieron nuevas funciones" (Silva, 2006: 387).

MAPA, por su parte, se situaba en el novedoso escenario urbano y emergente corredor financiero de la capital mexicana. En el número 56 de la Avenida de la Reforma, Francisco Borja Bolado y un pequeño grupo de colaboradores dio a conocer la revista MAPA, publicación mensual de la editorial Mercurio. Con la revista, iniciada en abril de 1934, dio forma a una aventura personal y a un proyecto intelectual que alentaba el conocimiento del país a través de un ojo entrenado. En el nuevo espacio editorial cumplió la doble función de director y gerente, es decir, orientaba la política de los contenidos y el diseño como la parte operativa para asegurar la edición cada treinta días.

La figura de Borja como creador y empresario se identificaba con el origen, como señala Dorotinsky, de "una nueva visualidad" abierta en los años treinta, con la "aparición de las revistas superilustradas" que, además, actuaban como "portavoces de la modernidad" (Dorotinsky, 2008:

La labor de Anesi en Argentina reconoce una influencia directa para la formación del "contenido, formato y estilo" en la National Geographic Magazine, así como también en la invención de "estereotipos dominantes sobre España y los españoles" en los Estados Unidos, (Zusman, 2012: 82; García, 2013). El editor de la revista MAPA, no dio a conocer dicha influencia como idea inicial del proyecto que encabezó desde México, aunque se constata una aproximación a dicha revista, por ejemplo, en el discurso visual por el uso de la fotografía de paisajes. 
7; Silva, 2006; Mraz, 2001: 117; Leidenberger, 2012). Así se situaba la nueva revista de Borja, que se propuso publicar en sus páginas las riquezas, tradiciones y valores mexicanos con la finalidad de dar a conocer México tanto a los mexicanos como a los visitantes extranjeros. La atención se centraba en un personaje nuevo: "el que viaja por su gusto" (MAPA, 1934: 6). Identificada esta figura por la revista como el "turista", era un viajero cada vez más visible y sensible, al que era necesario enseñar la cultura del viaje. Desde este proyecto editorial el viaje se entendía de una forma moderna como "el placer de las mudanzas del paisaje", es decir los cambios que el viajero experimenta con la mirada por medio del automóvil, el tren, el barco o el avión. El viaje representaba la posibilidad de "recrear los ojos y descansar la mente" (MAPA, 1934: 6).

El viaje, para la revista MAPA, no se improvisaba y, por eso, respondía a un tipo de viajero que contaba con tiempo libre, nuevas inquietudes e interés por ciertas prácticas que relacionaban lo espacial e histórico con la experiencia. En la vida social mexicana este perfil era una práctica cultural compartida por las clases medias y altas caracterizadas por su crecimiento económico y liderazgo social, unos valores identificados con la modernidad (Loaeza, 2012: 28). Estas clases sociales subsistieron al conflicto revolucionario, entre 1910 y 1917, sufrieron la exclusión "en gran medida del poder", de 1924 a 1934 y "vivieron la amargura de la marginación política" durante el gobierno de Cárdenas (Loaeza, 2012: 66 y 78), con quien entraron en conflicto por el radicalismo en el tema educativo ${ }^{5}$. Las clases medias contaban con una "identidad cultural" integrada por ciertas cualidades como la estabilidad y movilidad social, las aspiraciones de ascenso social a través del consumo ${ }^{6}$ y la educación como la base de su prestigio social (Loaeza, 2012: 35-40). Las clases medias de México alcanzaron un estilo de vida en los años treinta no sólo con la posesión de diferentes bienes, como una casa particular, sino a la manera de cómo los utilizaron (Loaeza, 2012: 40). Entre los bienes de consumo que adoptaron en sus vidas se encontraba el automóvil que les permitía exhibirse de una forma distintiva e imponer este objeto cultural como ideal al resto de la sociedad mexicana, como sucedió en los Estados Unidos (Shaffer, 2001; Edensor, 2004).

La incorporación del automóvil entre los elementos de la identidad social de las clases medias y altas formaba parte de la satisfacción material de los nuevos tiempos y de la motorización del paisaje mexicano. En esta nueva circunstancia se posicionaba la revista MAPA que impulsaba y preparaba, con el proyecto editorial, una percepción y sensación entre los lectores del paisaje mexicano. Con la autonomía que brindaba el automóvil se abrieron vías cada vez más amplias y novedosas para estimular los contactos culturales con lo mexicano, una perspectiva que MAPA compartía con otros proyectos editoriales de la época, particularmente con la revista "Mexican Folkways", que se publicaba desde 1925 bajo la dirección de Frances Toor quien buscaba lo nacional y la apreciación de la cultura y las artes del campo mexicano (López, 2010: 103).

\footnotetext{
Durante el cardenismo, la educación quedó bajo el control del Estado y al servicio de una integración nacional con contenidos específicos de la doctrina socialista (Loaeza, 2012: 105). Cárdenas miraba a las masas obreras y campesinas como "el factor fundamental del cambio social" (Loaeza, 2012: 93). Una profunda desconfianza creció entre la clase media, indica Soledad Loaeza, "frente al intervencionismo estatal en el terreno de los derechos del individuo", a la que se sumó la "defensa de los valores y costumbres asociados a la cultura católica, identificados como de una auténtica tradición nacional" (Loaeza, 2012: 95).

Uno de los signos del triunfo de la mentalidad burguesa, señala José Luis Romero, era el consumo y su expansión al resto de la sociedad con la creación de un contexto de "formas de vida, el predominio de la familia, la asimilación del prestigio social con la riqueza, el valor sacrosanto del trabajo y el lucro" (Romero, 1989: 141).
} 
Ambas revistas compartieron la edición bilingüe, nada más que "Mexican Folkways" se situaba en el tránsito del nacionalismo cultural de los años veinte a los treinta, al frente de las tradiciones, el folclor, el arte popular y la identidad del pueblo con el pasado, entre otros temas, aspectos que también interesaron a Borja para su revista, sin embargo, los objetivos de MAPA buscaban enseñar el paisaje a través del placer del viaje. En MAPA se ordenaron numerosas secciones a lo largo del proyecto editorial, cada una incidió en diverso modo en una cultura del viaje basada en el uso y propagación del automóvil a partir de la Ciudad de México. La primera sección, el "Editorial", era el espacio reservado para el editor, cada mes contaba con una ventana de expresión de los intereses del proyecto editorial. Desde ahí se fijaban las opiniones sobre los temas de interés para la revista, como las carreteras, los modelos de vehículos, los reglamentos de tránsito, la protección del patrimonio representado por las antiguas construcciones coloniales, la señalización o el hospedaje. Ahí se resaltaba la actuación de los particulares, se anotaban sugerencias y críticas a la inacción o a la falta de coordinación de las autoridades, así como llamados a una política sobre la conservación de la mexicanidad y del "tesoro histórico y artístico" del país (MAPA, 1934: 5).

Desde el primer número de abril de 1934 se consolidaron con el tiempo las siguientes secciones: "Nuestros conventos", "Riquezas arqueológicas", "Montañas y volcanes", "Las obras de la naturaleza", "Tradiciones mexicanas", "Ciudades coloniales", "Artes populares", "Danzas mexicanas", "Fiestas típicas", "Ciudades pintorescas", "Nuestra capital”, "Ciudades históricas", "México viejo", "Pinturas mexicanas" y "Varios". Otros temas, en cambio, perdieron interés en la edición, como los dedicados a los recursos forestales, la flora mexicana, la arquitectura militar, la etnografía o el ciclismo. Entre las secciones se estudiarán a continuación tres importantes, la de "Caminos", de "Automovilismo" y de "Viajes y excursiones", ya que articularon un conjunto de estímulos sobre los viajes y de novedades dirigidas, cada mes, a los lectores sobre qué ver de la variedad de los paisajes mexicanos, por medio de los artículos y reportajes gráficos.

\section{Una empresa privada en la construcción del paisaje mexicano en el contexto estatal}

Borja Bolado se propuso, con su empresa privada, una tarea de enorme alcance y largo aliento con la publicación mensual de la revista MAPA. La oficina editora representaba un nuevo marco institucional abierto para la promoción del viaje, esto significaba la participación activa en la difusión de los nuevos gustos y, a la vez, el interés para convencer a un grupo de lectores de la adopción de esta actividad. Ambos elementos, tanto la creación del goce o del placer derivado de la observación y la contemplación como la promoción de la curiosidad y la predilección por los espacios formaban las bases para una nueva relación y construcción del paisaje mexicano.

Estos intereses trazados desde la iniciativa privada, formaban la idea central del proyecto mensual de la revista MAPA. Lo principal del trabajo que impulsaba Borja se centraba en una oferta de contenidos de orden natural y social que brindaban variedad a la revista. La publicidad ocupaba su lugar en las páginas a través de los anuncios que le daba a la revista un sustento económico y se asociaba con la fotografía para incitar entre los lectores el consumo desde las artes gráficas?.

Sobre el potencial de la fotografía moderna asociada a la renovación de la publicidad, en los años treinta, véase: Català (2015). 
En este apartado se revisará ¿cómo era la participación de esta iniciativa privada en la construcción del paisaje mexicano a través de las páginas de la revista MAPA? Se ha formado, en primer lugar, una contabilidad de los artículos publicados en las secciones elegidas, antes indicadas, misma que se presenta en el Cuadro $N^{\circ} 1$, con la indicación del número de colaboraciones por año.

\section{Cuadro $N^{\circ} 1$}

La formación de una cultura del viaje y del paisaje mexicano, 1934-1940

\begin{tabular}{|l|r|r|r|r|r|r|r|r|}
\hline Sección/Año & \multicolumn{1}{|c|}{1934} & \multicolumn{1}{|c|}{1935} & \multicolumn{1}{|c|}{1936} & 1937 & 1938 & 1939 & 1940 & Total \\
\hline Caminos & 5 & 8 & 7 & 2 & 2 & 15 & 3 & 42 \\
\hline Automovilismo & 12 & 39 & 22 & 19 & 16 & 31 & 31 & 170 \\
\hline Viajes y excursiones & 5 & 10 & 6 & 10 & 7 & 7 & 12 & 57 \\
\hline Total & 22 & 57 & 35 & 31 & 25 & 53 & 46 & 269 \\
\hline
\end{tabular}

Fuente: MAPA Revista de Turismo, 1934-1940.

Esta tríada articulaba, desde la revista, la formación de una cultura del viaje que relacionaba a los viajeros con los lugares y la nueva movilidad impulsada por la política de Lázaro Cárdenas a través de proyectos de largo alcance territorial: la carretera de México a Nuevo Laredo abierta en 1936 y la de México a Morelia y Guadalajara en 1939. Estas obras, a la vez, impulsaban el automovilismo, por lo que el tema ocupaba una sección importante de la revista MAPA, sobre todo a partir de que la sección de "Automovilismo" era adoptada como apartado oficial de la Asociación Mexicana Automovilística (AMA), una asociación civil fundada en Monterrey, en 1929, a raíz de la apertura de la carretera de Monterrey a Nuevo Laredo, con la finalidad de facilitar los trámites y el ingreso de coches por esa frontera norteña procedentes de los Estados Unidos. Con esto se incrementaron las opciones del viaje y las excursiones en todas direcciones, como se verá a continuación. El ferrocarril, el barco y el avión, por su parte, también encontraron su lugar en las páginas de la revista MAPA bajo una nueva manera de ver los contenidos culturales del paisaje mexicano.

\section{Caminos}

En esta sección se registró un total de 42 artículos en el periodo de 1934 a 1940 que abarcaron una variedad de temas que a la revista le interesaba centrar y resaltar. La sección informaba al viajero de la situación, la construcción y la apertura de las carreteras, uno de los sectores que rápidamente recibió una mayor atención en el nuevo gobierno federal. La red de caminos en 1930 era de 1.426 kilómetros, de los cuales 541 eran pavimentados y, diez años después, alcanzaron los 9929 kilómetros, de ellos 4.781 eran pavimentados, lo que representó pasar la inversión total de 7,5 a 38,2 por ciento en el renglón de los caminos y puentes (González, 1990: 52). Los nuevos caminos se relacionaban con el impulso industrial de Monterrey y de Sabinas y, desde ahí, con los intercambios comerciales hacia los Estados Unidos (Harber, 1992). Por su parte, otro camino desde la capital mexicana se dirigía a los lugares coloniales e históricos como Morelia y Guadalajara. Cada itinerario, por tanto, contaba con características específicas, por lo que esta sección de la revista proporcionaba al viajero la información puntual y precisa de los caminos. 
Mientras que la construcción de los caminos buscaba la articulación de la capital mexicana, el incremento de los automóviles, en los años treinta, transformó los desplazamientos de las personas y las preferencias del viaje. Para 1934, el número de automóviles era de 108.000 (74.000 vehículos de pasajeros, más 34.000 vehículos comerciales) y, para 1940, pasó a 146.000 (94.000 vehículos de pasajeros, más 52.000 vehículos comerciales), (Mitchell, 2007: 613). Las autopistas construidas en los años treinta dejaban atrás la tortura del viaje y los viejos caminos afectados en la temporada de lluvias. Además, el automóvil ganaba popularidad entre las clases medias por la vía del crédito que otorgaban las agencias, con lo que se convirtió en un transporte y tecnología individual que cambiaba la vida humana (Freeman, 2012a; Giucci, 2007).

La nueva cultura del viaje quedaba señalada en el primer número, de abril de 1934, de la revista MAPA: "el mexicano comienza por conocer su propio país antes que le muestren los del exterior y se pasme ante las bellezas naturales que tiene en su casa. Se familiariza así, con los itinerarios y se hace amigo de la geografía, que nos complacemos frecuentemente en ignorar" (MAPA, 1934: 7). Esta mención señalaba que esta iniciativa privada constataba el valor de la geografía y dirigía nuevas ideas e intereses para su promoción desde los espacios impresos. Nada más abrir el primer número se recomendaba al lector la nueva carretera escénica hacia el puerto de Acapulco (abril) y, hacia el poniente, una ruta con perfil montañoso y frio hacia Toluca (mayo). Dejaba ver su atención en las obras de la carretera hacia Nuevo Laredo (septiembre) y la nueva ruta en los confines de la capital, desde San Ángel al Desierto de los Leones (octubre). Para la primavera de 1935, la revista MAPA presentaba dos rutas hacia al oriente de la capital mexicana, a Puebla (marzo) y la otra a las Huastecas (abril), para terminar con una salida en invierno a Tenango del Valle (diciembre).

Un año después, presentaba un amplio foto reportaje de más de sesenta páginas por la apertura de la carretera de la Ciudad de México a Nuevo Laredo (julio). El viaje requería, ahí se indicaba, de tres jornadas diurnas, primero, hasta Valles (473 kilómetros), luego de ahí a Monterrey (517 kilómetros) y con una conexión a San Antonio, Texas (480 kilómetros), con lo que, se indicaba a los lectores, se conseguía "una síntesis visual de la República Mexicana en sus más variados aspectos" (MAPA, 1936). La carretera se consideraba el triunfo de la mano del hombre sobre la naturaleza por los puentes metálicos sobre arroyos y ríos (Secretaría, 1936). La ruta dejaba abierta por primera vez una variedad de paisajes a los viajeros de los Estados Unidos que, de manera autónoma con sus coches, accedieron a nuevos contenidos culturales del paisaje, como antiguos asentamientos coloniales, grandes extensiones agrícolas, una variada vegetación tropical, las obras de irrigación y las ciudades industriales (Departamento, 1936; Shaffer, 2001; Freeman 2012b).

En el número de agosto de 1936 se incorporaba otra experiencia de viaje en coche a Acapulco $y$, finalmente, la salida a Malinalco cerraba las opciones de ese año (diciembre). La noticia principal, en el número de abril de 1937, era el proyecto de la carretera de Guadalajara a Nogales, promovida por la AMA entre los gobiernos, federal y estatales, además de los particulares, una obra de 1.732 kilómetros de longitud que pasaría por los estados de Jalisco, Nayarit, Sinaloa y Sonora. Al unirse con la carretera nacional número 4 de la Ciudad de México a Guadalajara alcanzará los 2.431 kilómetros, con lo que se abriría una de las más largas vías de comunicación del país, junto con la de Laredo, para los viajeros procedentes de los Estados Unidos. Además de la conexión con los lagos de Chapala y Pátzcuaro, esta ruta del Pacífico ofrecería al automovilista una variedad de paisajes, entre arquitectura colonial del siglo XVI y bellezas panorámicas combinadas con 
las marismas y las playas de Sinaloa, más adelante, el coche atravesaría los grandes ríos, en este orden, el Fuerte, el Mayo y el Yaqui que suministraban el agua que, con los tractores segadoras, engavilladoras, sembradoras y trilladoras, transformaban el paisaje agrícola entre Los Mochis, Navojoa y Ciudad Obregón para seguir el camino hacia Hermosillo y Nogales.

En el número de abril de 1938 se daba información precisa de las condiciones de los caminos, así como las obras en curso y las condiciones de tránsito. En 1939 la AMA informaba de los trabajos en los caminos de Nogales (julio), de Acapulco y de San Luis Potosí (septiembre). Las rutas hacia Orizaba y Córdoba o la de Jalapa al puerto de Veracruz se presentaban al lector como opciones para el fin de año (diciembre). La apertura de la carretera de la Ciudad de México a Guadalajara ocupaba la mayor atención del número de junio de este año. La revista dedicó más de sesenta páginas para describir, a través de mapas, el kilometraje de cada tramo para estimar los tiempos del viaje. La ruta también conocida como "Internacional del Pacífico", abierta el 22 de noviembre de 1939, contaba con una longitud total de 685,5 kilómetros y 34 puentes modernos (Secretaría, 1939:59). Tal novedad merecía toda la atención de la revista y el énfasis transmitido a los lectores de hacer dicha travesía con la recomendación de hacer escalas en Morelia, Pátzcuaro y Uruapan antes de seguir a la capital tapatía y a destinos cercanos como Chapala, Juanacatlán y Zapopan.

Para 1940, la revista invitaba a los lectores a una ruta diferente para la primavera de ese año (marzo). Un camino cortado por una sucesión de paisajes: primero por el convento agustino de Acolman, la vegetación tropical de Tancanhuitz y el ingenio azucarero de El Mante. El trayecto terminaba en Tampico, el segundo puerto del país y el núcleo de la industria petrolera. Los hoteles, clubes deportivos y balnearios aguardaban al viajero, y actividades como la pesca en la laguna de Tamiahua y la caza por el interior, además, la excursión se prolongaba a Ciudad Victoria y a Monterrey. En el mismo número se presentaban cincuenta páginas con cuatro opciones automovilísticas para cerrar el año: Acapulco, Veracruz, Córdoba y Guadalajara.

\section{Automovilismo}

Esta sección de la revista suministraba una gran cantidad de información al lector. Desde el primer número de abril de 1934 hasta 1940 se registró un total de 170 artículos, entre notas, noticias e informes técnicos tanto de la cultura del manejo, como de las características y mantenimiento del automóvil y de las carreteras. A través de las páginas de la revista se entregaban cada mes una serie de consejos al conductor para evitar accidentes, noticias del reglamento de tránsito e información de los servicios de emergencia, así como sobre la labor de la AMA. En esta sección, el lector se mantenía informado del mundo automovilístico en los principales centros de Estados Unidos, Alemania o Inglaterra, como de la realización de convenciones y del famoso salón del automóvil en París. Además, esta sección mostraba la presentación de los coches para el año siguiente, con las imágenes de los modelos y las novedades de cada marca. Esto consolidaba una alianza al interior de la empresa privada a favor del uso del coche, la promoción del viaje entre particulares y el gusto por el paisaje mexicano visto desde el auto y al alcance mediante la apertura de las carreteras.

De esta manera, la revista MAPA se convertía en una ventana con resonancia en la socialización y motorización de la vida mexicana. Al inicio de la edición, en el número de junio de 1934, se anunciaba la instalación del Club Automovilístico del Distrito Federal, una filial de la AMA abierta en el centro de los caminos del país e integrada por un grupo selecto de 300 socios, entre los que 
se encontraban políticos, arquitectos, ingenieros, médicos, licenciados y militares. La membresía tenía ventajas entre los conductores de ambos sexos, como el auxilio en el caso de accidentes, la tramitación en la oficina de tránsito, la de seguros contra accidentes y robos, y la publicación de guías y mapas de los caminos mexicanos (MAPA, 1934).

Esta organización abierta por la AMA, que coordinaba los servicios de la oficina de Monterrey y la del Distrito Federal, buscaba la promoción nacional y, en el caso de la procedencia internacional, facilitaba los trámites de migración y aduanas de los viajeros de los Estados Unidos que se dirigían a la capital neolonesa y a Saltillo para continuar el viaje automovilístico hacia Ciudad Victoria, El Mante y Tampico. Este grupo recibió particular atención por parte de la AMA a través de la publicidad insertada en los mapas de la "American Automobile Association" (AAA), con anuncios en los periódicos, en las radiodifusoras de Texas y con la distribución de una gran cantidad de folletos sobre las carreteras y sobre México (Departamento, 1936). Por esta labor, los coches aumentaban su presencia por la carretera nacional número 1 o Panamericana. En las páginas de la revista, la AMA publicaba el incremento de las cifras: de 2.735 coches en 1929, pasó a 4.421 en 1930, 6.462 en 1931, 6.512 en 1932, 8.690 en 1933 y 12.123 vehículos internados en 1934 y se esperaba el aumento de la cifra a 1.500 mensuales una vez completada la construcción de la carretera hasta la capital mexicana (MAPA, 1934: 64).

La labor de la AMA, señalada en la revista, se enfocaba a promover el automovilismo no como "deporte o lujo social, sino como servicio utilísimo al alcance de las mayorías" (MAPA, 1934: 65). La relación abierta entre el automovilismo con las carreteras, creaba dentro de la AMA una opinión favorable de las acciones que, desde el gobierno federal, se realizaban en materia de construcción de caminos. En este asunto había un punto de acuerdo de cooperación de la iniciativa privada con el gobierno federal para unir intereses en beneficio de la economía nacional, de los viajeros y de la conservación de los "monumentos" y la promoción de las "regiones típicas y pintorescas" de México (MAPA, 1934: 65). La AMA atendía, en sus oficinas de Paseo de la Reforma, número 46, las necesidades de los socios, por ejemplo, sobre cómo visitar el Convento del Desierto de los Leones o elegir la mejor ruta para ir en coche de la Ciudad de México a Nueva York, también contaban con otros servicios, como los boletos de avión, cheques de viajero, timbres postales 0 la reservación de hospedaje (MAPA, 1934: 45). Al poco tiempo abrieron oficinas en Puebla y en Acapulco. La AMA atendía reservaciones de alojamientos en Guadalajara, Toluca, Puebla y Veracruz. Con este servicio añadido, se garantizaba el "conocimiento de los inconvenientes, peligros, peculiaridades y bellezas del camino" al menor precio (MAPA, 1935: 45).

La AMA emitía opiniones sobre el embellecimiento de los caminos a través del arbolado, con las técnicas de la arboricultura, para formar marcos naturales que "contribuyan a hacer resaltar los esplendores del paisaje" (MAPA, 1935: 27), también llamaba la atención sobre las señales de tránsito, sobre todo, en caminos secundarios cada vez más transitados por el viajero hacia "lugares de interés histórico, arqueológico colonial o panorámico" (MAPA, 1935: 39) y presentaba en sus páginas un plano de una moderna estación de servicio, para abrirse cada 120 kilómetros en las carreteras, para la venta de combustible y lubricantes, servicios de frenos, lavado, afinación del motor, reparación de neumáticos, acumuladores y alineación, todo esto, atendido por una excelente organización del personal (MAPA; 1935: 53). También sugería preparar un cajón de madera a modo de una "pequeña biblioteca portátil", con cajoncitos y divisiones para "papel de cartas, lápices, cigarros y caramelos" para escribir y enviar las experiencias del viaje (MAPA: 1936: 53). 
La AMA proporcionaba a sus socios la revista MAPA y les ofrecía el servicio de información sobre el alojamiento, víveres, gasolina, etc., de la historia y del interés de los lugares (MAPA, 1936: 89).

Estos elementos indicaban cambios en las facilidades del viaje, mismas que impulsaba la industria automotriz. La revista señalaba: en los coches "los asientos son ahora amplios, suaves y cómodos. Están tapizados de materiales agradables al tacto y de colores placenteros. La verdad no se ha dejado nada por hacer por convertir el automóvil en un instrumento de placer. En él el viaje puede ser agradable, seguro y rápido" (MAPA, 1936: 48). Con tal visión y alcances en el estilo de manejar un coche, se esperaba la ampliación de la carretera nacional número 1 o Panamericana, que llevaría a los viajeros desde Canadá, los Estados Unidos y México hasta Panamá, un itinerario que traspasaba las fronteras internacionales y hacía soñar en una nueva época bajo el dominio del coche, largos trayectos y nuevas experiencias del viaje relacionadas con el paisaje (MAPA, 1935: 70) (Figura No 1).

Figura $\mathrm{N}^{\circ} 1$

El inicio de la motorización del paisaje mexicano

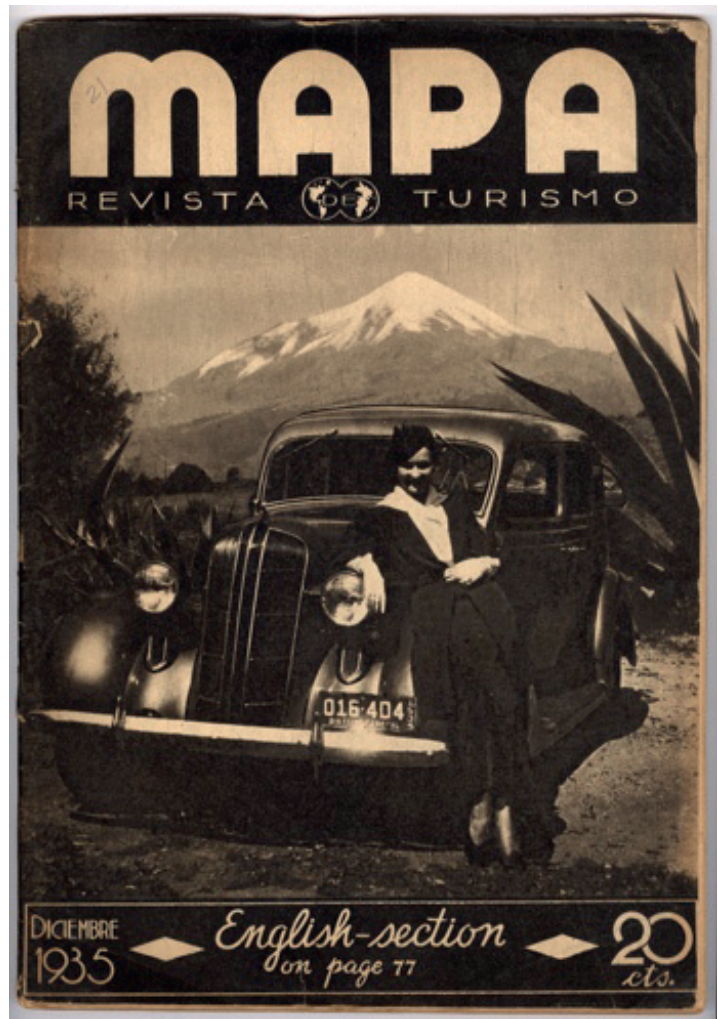

Fuente: MAPA, diciembre 1935, portada.

Algo significativo de esta sección de la revista era el cambio de la mentalidad a lo espacial: "Ya tiene menos sentido para nosotros el decir que nos hallamos a 94 kilómetros de Pachuca, que el decir que nos hallamos a dos horas de distancia de esa ciudad" (MAPA, 1935: 46). La presencia del automóvil enfrentaba al viajero no solamente a las nuevas emociones y experiencias corporales 
y visuales, también al acercamiento y la nueva percepción de las distancias. Este punto señalaba a las nuevas tecnologías en la exploración del espacio y el camino abierto hacia la construcción de una cultura de lo nacional, del que participaban la fotografía, el mapa y el paisaje (Jolly, 2014). Por esto, conviene recuperar un planteamiento del editor desde la revista: “Qué sabían de México los mexicanos de ayer?" La situación ameritaba una reflexión, no solo sobre los rápidos cambios vividos en esos años, sino también sobre lo mexicano de la siguiente manera:

"Tasco, Acapulco, por ejemplo, eran países casi legendarios para nuestros abuelos. Su mexicanidad era un concepto poético, apenas apoyado en la geografía. Ahora, en cambio, Tasco y Acapulco nos inspiran un sincero interés. Ahora si ya pertenecen al corazón nacional. El automóvil ha logrado que los reabsorbamos. Y otro tanto podemos decir de todos aquellos sitios que en nuestra cultura realiza, mediante el automóvil, su penetración. Y al mismo tiempo que los incorporamos, ya de un modo práctico, a nuestra patria y a nuestros afectos, les llevamos nuestra civilización [a] esos pueblos que nos eran hasta ayer desconocidos. La influencia del automóvil no es románticamente sentimental, sino social. Cada automovilista que vuelve de un lugar, vuelve con un nuevo sentimiento de simpatía y de comprensión" (MAPA, 1935: 46).

Tales eran los alcances sociales de la construcción de los caminos modernos, de la conexión de las fronteras internacionales, de los efectos sociales de la nueva movilidad, de la formación del gusto por el viaje en coche y de la adopción del automóvil entre las clases medias. En los viajes y excursiones de los años treinta surgieron nuevos comportamientos y relaciones con los rasgos geográficos de remotos orígenes y vestigios culturales aún desconocidos del paisaje. Estas prácticas promovieron nuevas maneras de pensar lo nacional que, en buena medida, buscaba la construcción de una cultura sobre el paisaje mexicano, como se examinará a continuación.

\section{Viajes y excursiones}

Esta sección de la revista MAPA presentaba cada mes una variedad de opciones de viaje a los lectores. En el periodo de 1934 a 1940 se contabilizaron 57 artículos con distintos lugares, tanto de la capital mexicana, de las cercanías y más allá, con salidas que requerían de una mayor planeación y organización por parte del viajero y, sobre todo, con base en información puntual que se ofrecía a los lectores en las páginas de la revista. A través de los contenidos de esta sección, la revista integraba una visión novedosa del paisaje mexicano, lo que otorgaba respaldo al viajero y a las ideas del viaje que se transmitían a través de la información e imágenes. La preferencia por el viaje en coche, en contadas ocasiones, dio lugar al ferrocarril, al barco y al avión que también guiaron la mirada del lector hacia los contenidos culturales del lugar, como se verá más adelante.

El desplazamiento desde un espacio local o restringido a otro distante volvía próximo lo lejano, por esto, la revista opinaba que: "el mexicano comienza por conocer su propio país antes que le muestren los del exterior y se pasme ante las bellezas naturales que tiene en casa. Se familiariza así, con los itinerarios y se hace amigo de la geografía, que nos complacemos frecuentemente en ignorar" (MAPA, 1934: 7). Adentrarse en la geografía tenía ventajas para el viajero: "porque se renueva su visión interior con el cambio de paisaje" (MAPA, 1934: 7). En el primer número, de abril de 1934, la revista recomendaba el viaje a Acapulco, al que se llegaba luego de doce horas continuas de manejo en coche, con una escala en Taxco, hasta completar los 450 kilómetros de distancia de la llamada "ruta de los asombros" (MAPA, 1934:7). A partir de Chilpancingo, el trazo de grava, tierra y arena formaban el camino: los "autos corren por el laberinto de montañas, entre 
nubes de polvo. Es el camino una madeja de curvas múltiples" (MAPA, 1934: 8). El viajero pasaba por los paisajes, entre valles y montañas y, "de súbito, como al descorrerse un telón monumental, la bahía de Acapulco, azul, serena, magnífica, abierta y desdoblada en el horizonte. Es una visión que deja suspendido el ánimo del viajero. Allí está el viejo Mar del Sur" (MAPA, 1934: 11).

Ir a Acapulco era uno de los viajes en coche más atractivos que registraba la revista y el que varias veces será objeto de recomendaciones para el viajero en las siguientes ediciones. Éste, manos al volante, comprobaba el encanto de los paisajes en la ruta y el surgimiento de una mezcla de sentimientos y pensamientos entre su procedencia, lo que quedaba atrás y ese presente que brindaba el viaje lleno de emociones, el placer del mundo, las sorpresas, las ensoñaciones y las reflexiones, las variaciones climáticas de la ruta, el paisaje heredado en cada lugar con las iglesias y leyendas y, de pronto ante sus ojos, el mar con sus tonalidades azul y verde, la inmensidad del Pacífico.

Comenzada la aventura ese año, la revista insertaba, sobre todo, una pluralidad de opciones para el viajero con rutas que contrastaban el paisaje, por su clima o por los vestigios culturales. También por la cercanía como al Desierto de los Leones, a las afueras de la capital mexicana (mayo) y otra más alejada, atravesada por montañas y ríos, en Jacala, Hidalgo (agosto). La lista de sugerencias cerraba ese año con cuatro playas: Mazatlán, Veracruz. Acapulco y Tampico; cuatro ciudades: Morelia, Querétaro, Guanajuato y Guadalajara y cuatro rutas automovilísticas: Pachuca, Cuernavaca, Puebla y Toluca (septiembre). Al año siguiente, la revista presentaba las opciones de primavera, con una amplia propuesta por Puebla, para visitar los paisajes de Acatlán, Cholula, Teziutlán, Chalchicomula, Cuetzalan, Atlixco, Azcopan y Acatzingo (abril). Dentro de esa temporada, la revista sugería, esta vez, una salida en ferrocarril a Veracruz, la ruta tradicional e histórica. El tren sorprendía al viajero, cerca de Córdoba, el "tren camina por entre las fértiles tierras veracruzanas. El paisaje es variado e interesante. Una caída de agua. Un puente metálico. Unas casitas blancas entre el verde de la montaña y que semejan despeñarse. Un fuerte olor a vainilla" (MAPA, 1935: 8). Mientras que el viaje a las Huastecas (mayo), llevaba al viajero por una carretera escénica, entre Pachuca y Molango, que contaba con haciendas, cascadas, grutas e iglesias, sumergidas entre bosques y montañas, para combinar estos elementos heredados del paisaje con la modernidad de los servicios telefónicos, de la venta de gasolina en las estaciones de servicio abiertas a lo largo del camino y el hospedaje disponible al final de la ruta.

La revista recomendaba para los viajes y excursiones de 1936 cuidarse de las quemaduras producidas por los rayos solares y de los mosquitos que, en algunas partes del país, podían transmitir enfermedades como el paludismo y el dengue; alertaba del fuego usado para alumbrarse o calentarse y moderarse en las marchas, al principio, con paseos cortos y aumentar la distancia progresivamente. Para la primavera, la revista alentaba a los lectores a salir: "Escapar de la ciudad... Ir al campo, a la montaña, a la playa, a la ciudad reposada y vetusta". Esa vez, se repetía el paisaje marítimo del año anterior: Veracruz y Tampico por la franja oriental y Acapulco y Mazatlán en la costa del Pacífico (MAPA, 1936: 9). Por eso, en el número de abril, estrenaron una ruta que combinaba la cálida y húmeda costa con el interior montañoso, se llevaba al lector a Coatzacoalcos, desde ahí, el viaje en coche se dirigía por la carretera hacia Minatitlán y, atravesado el istmo, hasta Juchitán, Tehuantepec y Santa Lucrecia (MAPA, 1936: 7).

En mayo, la revista presentaba un foto reportaje diferente a todo lo anterior: el viaje en avión. La empresa Aeronaves de México ofrecía el servicio tres veces a la semana (martes, jueves y sábados) de la capital mexicana a Acapulco y, en tan solo ochenta minutos, el viajero "variará de clima, de 
altitud, de costumbres, de humores, de vestido y de alimentación". La elevación del avión cambiaba la perspectiva e integraba en una síntesis todo cuanto se apreciaba desde lo alto, en "una aventura inolvidable y deliciosa" (MAPA, 1936: 17). El foto reportaje se acompañaba de un total de seis fotografías en blanco y negro que formaban una secuencia visual: primero una vista panorámica de la bahía de Santa Lucía, seguida de otras cuatro fotografias aéreas oblicuas del litoral, que daban una idea de la potencia de los arrecifes y acantilados, cerraba una fotografía del caserío del puerto. Las imágenes daban una idea precisa al lector del imponente horizonte, al aproximarse, el avión pasaba rasante por los cerros: "Un paseo rápido sobre olas y quebradas, arrecifes y playas. Leemos el plano de la configuración de Acapulco y sus aledaños. El avión aterriza isanos y salvosi" (MAPA, 1936: 22). Este viaje cambiaba "la manera de ser de las personas" tanto por las emociones como por las enseñanzas al ver hacia abajo el gigantesco mapa vivo desde el avión

La revista MAPA entregaba, para 1937, una propuesta editorial nueva y, sobre todo, con mayores alcances para el viajero. En el número de marzo de este año, se incorporaba una clasificación de las excursiones en cuatro categorías: de uno, dos, cuatro y hasta diez días. Un mapa registraba la salida desde la capital mexicana, las diferentes rutas abiertas y los lugares (Figura $\mathrm{N}^{\circ} 2$ ), por su parte, una serie de guías ordenaban la información de los servicios de autobuses, de los "pulman" y, en los casos de los lugares alejados, del ferrocarril y del avión. Con esto, se ofreció una variedad de rutas y lugares del país que el lector podía elegir anticipadamente a partir de la información e imágenes aportadas en las páginas de la revista. El mapa registraba las primeras salidas o más cortas de duración, equivalían a unas horas a las Lagunas de Zempoala, Tepoztlán, Actopan, Teotihuacán y Amecameca. Las de dos días se dirigían a Cuernavaca, Taxco, Tlaxcala, Pachuca, Cuautla, Jacala y Cacahuamilpa. Las de cuatro días, se alejaban de la capital mexicana hacia Puebla, Querétaro, Guanajuato, Morelia, Tenancingo, San Miguel Regla, El Mante, Tehuacán y Chignahuapan. La serie mayor indicaba excursiones de diez días a Jalapa, Mazatlán, Mérida, Orizaba, Pátzcuaro, Monterrey, Guadalajara, Acapulco, Oaxaca y Alvarado (MAPA, 1937: 10).

Figura $\mathrm{N}^{\circ} 2$

La Ciudad de México: el centro de la cultura del viaje.

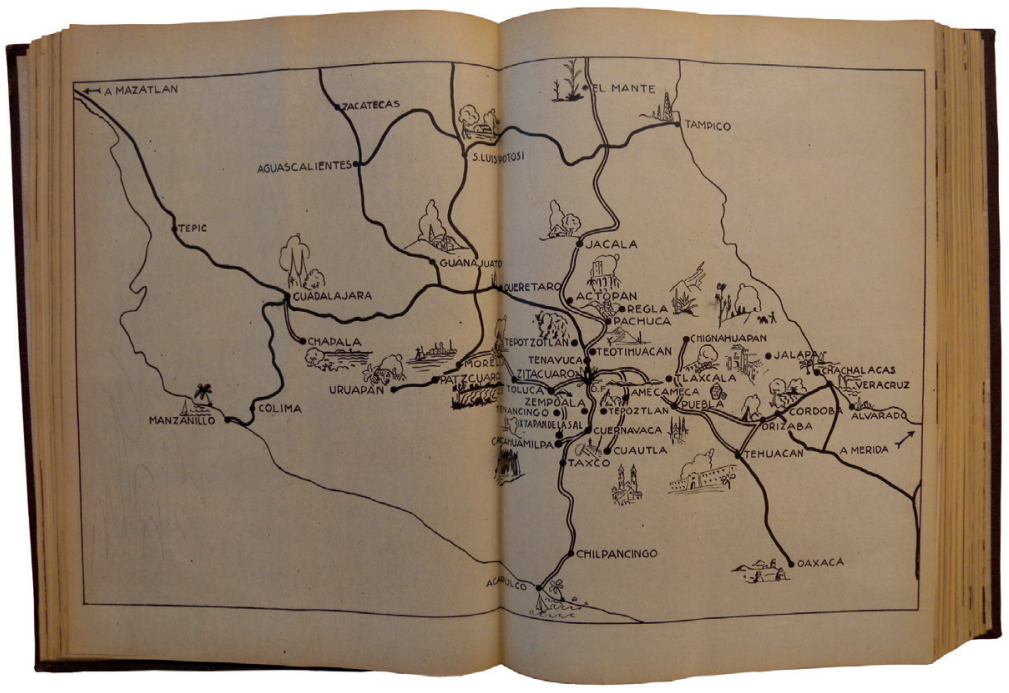


Abierta la nueva ruta hacia el norte mexicano, desde 1936, se animaba a los lectores a un largo trayecto automovilístico, de casi mil kilómetros, hacia el paisaje industrial y a Laredo, Texas (Figura $\mathrm{N}^{\circ} 3$ ). Monterrey actuaba como ancla de un itinerario de diez días que pasaba del paisaje colonial de Pachuca y Tamazunchale al clima cálido en Ciudad Valles y al espíritu provinciano y colonial de Ciudad Victoria donde esperaban al lector las huertas con árboles de naranjas, limas, plátanos y piñas. En Monterrey había tres opciones para el viajero. Los edificios del gobierno, escuelas y hospitales, así como la Catedral y las plazas de la ciudad; después, la visita a las fundiciones, las fábricas de vidrio, mosaicos, fósforo, muebles, productos alimenticios, conservas, cerveza, lámparas y maquinaria; se terminaba con las excursiones al salto de agua o Cola de Caballo, los manantiales de Topo Chico, el bosque en Chipinque, el edificio del Obispado y las grutas de García (MAPA, 1938: 37). En 1938 se sugería una ruta de Orizaba al puerto de Veracruz y otra más larga de diez días por el paisaje martítimo veracruzano (MAPA, 1938: 10).

Figura $\mathrm{N}^{\circ} 3$

Las obras técnicas que construyen el paisaje moderno. Puente de la carretera México-Laredo

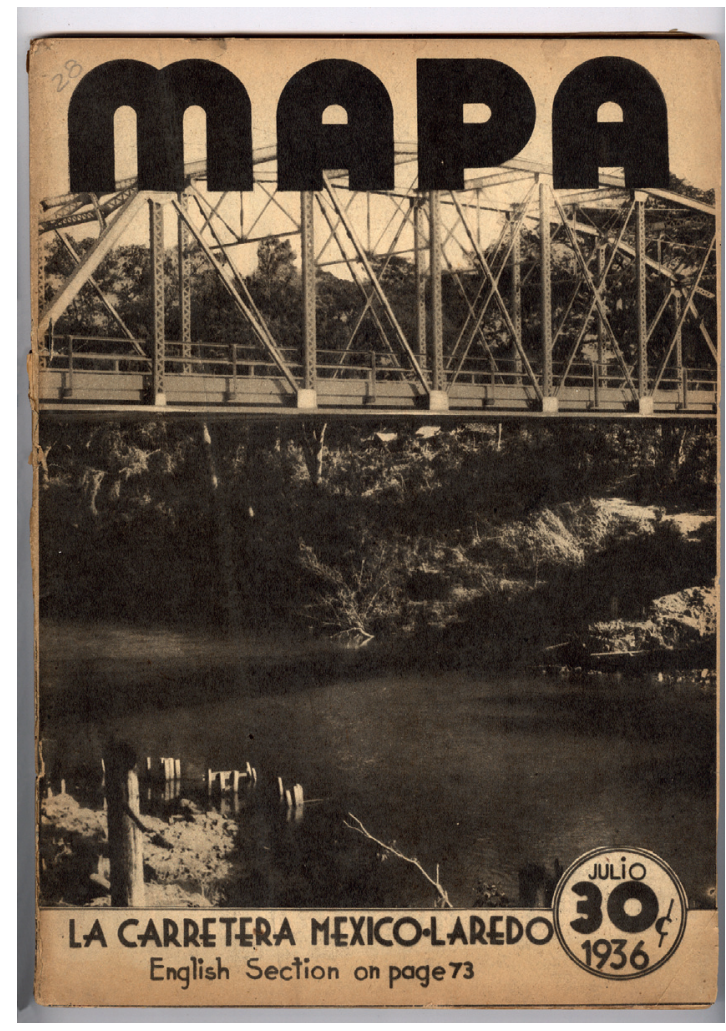

Fuente: MAPA, julio 1936, portada.

La otra ruta norteña se presentó al año siguiente, esta vez, con una salida en el ferrocarril de la capital mexicana a la frontera con los Estados Unidos, a través de una variedad de paisajes coloniales y grandes cultivos de fresas, cactáceas y largas Ilanuras. Un artículo, de enero de 1939, festejaba el quinto año de vida de la revista con esta recomendación por el centro del país, el más largo hasta ese momento, por Hidalgo, Querétaro, Guanajuato, Aguascalientes, Zacatecas, Duran- 
go, Chihuahua y Ciudad Juárez (MAPA, 1939: 23). En abril de este año, la revista ordenaba cinco rutas desde la Ciudad de México hacia Acapulco, Córdoba, Veracruz, Guadalajara y se volvía a la de Laredo en conexión con San Antonio, Texas. Una más salía en ferrocarril a Guadalajara, Mazatlán y terminaba en el puerto de Guaymas, Sonora. El año terminaba con un foto reportaje, de diez páginas y 26 fotografías, de la "Excursión Barnard" que se organizaba en barco de Acapulco a Zihuatanejo (MAPA, 1939: 11). Con una duración de seis días, este viaje buscaba no nada más apreciar el paisaje marítimo, sino convertir el desafío de vivir una experiencia casi sin ninguna presencia del mundo moderno y sin comunicaciones por tierra, en una aventura placentera. A través de las imágenes se apreciaba que Zihuatanejo era un espacio, sobre la costa del Pacífico mexicano, con la potencia de trasladar al viajero a un paisaje con aspecto de remotas temporalidades.

Un amplio reportaje invitaba a los lectores a visitar Tampico, el núcleo de la industria petrolera recién nacionalizada que combinaba varias atracciones para los lectores. El número de marzo de 1940, entregaba un foto reportaje de la carretera, de 727 kilómetros desde la capital mexicana. Un grupo de fotografías mostraba una combinación de paisajes, con rasgos culturales de remota procedencia a lo largo de la ruta, como los conventos de San Agustín Acolman, de Actopan, Ixmiquilpan y Altamira. Las variantes de este paisaje se cruzaban con vestigios arqueológicos, huertas y campos agrícolas y puentes metálicos sobre ríos. La vegetación de palmeras anunciaba la llegada a la Huasteca, la tierra del petróleo. Una vez en el puerto, varias opciones se abrían para los viajeros, como la visita al paisaje edificado: la aduana, la Compañía de Luz, el de Correos y Telégrafos o el de Alijadores, la Compañía Telefónica y la Cruz Roja, el Palacio Municipal, la Plaza de Armas y la Catedral. Después los jardines (del Águila, las Flores, la Minerva y el Country Club) y la colonia "El Águila". El mar y las playas centraban la mayor atención del paisaje marítimo por el contacto con la arena, la animada vida en los balnearios, los barcos en la desembocadura del río Pánuco y la pesca en la laguna de Tamiahua (MAPA, 1940: 7).

En este apartado, en resumen, se integraron las secciones con los elementos que se combinaron, entre el gobierno federal y la participación de una empresa privada en la promoción de una cultura del viaje y la construcción del paisaje. La revista MAPA guiaba a los lectores, como se ha indicado al inicio, a través de una visión mecanizada por medio de los foto reportajes, la guía de los mapas y la información de los paisajes que cambiaban rápidamente, por lo que estas páginas se insertaban en lo que Monsiváis identificaba como el "rescate de los elementos nacionales y la esencia de los paisajes rurales y urbanos, el amplio interés por el descubrimiento del país y la construcción del patrimonio cultural" (Monsiváis, 1988: 1515). Integrada al catálogo de productos nacionales y en los gustos de la clase media y alta, MAPA señalaba los espacios vividos, la construcción de lo nacional y el paisaje "nacido en el pensamiento de una élite letrada" (Berque, 2009: 22).

\section{Conclusiones}

El intento de captar la sobreabundancia de paisajes mexicanos en las páginas de la revista MAPA, apenas comienza a conocerse desde la perspectiva de la geografía cultural. La revista, convertida en una plataforma editorial, procedió a la difusión de una pluralidad de elementos del paisaje, de forma coincidente con otras iniciativas del mundo editorial que asumieron la construcción de los paisajes de América Latina. MAPA era una ventana para asomarse a la geografía cultural de México, donde se ordenaba un mundo natural y cultural, en este caso, con el registro 
escrito, las imágenes y los mapas. De esta forma la revista actuaba como formadora de los nuevos gustos, a la vez que alentaba entre los lectores, desde la Ciudad de México, una forma de comprensión de lo nacional, identificado en sus páginas a través de las variables del espacio y tiempo mexicanos. A través de ella se abordaron en este trabajo los primeros elementos que atañen a la pregunta ¿cómo se construyó con este medio privado el paisaje mexicano en los años treinta del siglo $X X$ ?

La respuesta se ha ordenado a partir del análisis de los primeros años de la edición de la revista, entre 1934 y 1940, en el marco del cardenismo como régimen político que afianzó el poder del Estado en esos años. Cárdenas abrió una época de nuevas relaciones con las masas obreras y campesinas. Las clases medias, por su parte, consideradas por Soledad Loaeza (2012) por su liderazgo social y formas de vida basadas en el consumo, quedaron marginadas del poder político. Estos grupos sociales, en cambio, participaron en los ámbitos de la vida económica de México. En este contexto, este medio privado daba una aplicación de la geografía marcadamente ideológica a partir de qué se sugiere ver de los espacios vividos entre las clases medias y altas a partir de la identificación, en este trabajo, de los contenidos naturales y culturales del paisaje exhibidos en la revista MAPA, con lo que se buscaba un consenso y un sentido de identidad a la vida individual.

En este marco, la participación de esta empresa privada acompañó y legitimó las acciones estatales en términos de extensión de infraestructura. Las carreteras aumentaron a diez mil kilómetros en este periodo. Destacaba el nuevo enlace con los Estados Unidos y la llegada de nuevos viajeros en coche por carretera hacia destinos urbanos, rurales, de la montaña o la playa. Esto incidió en la promoción de la curiosidad y la conexión de la mirada con el paisaje a través de la ventana del coche. MAPA, además, era la fuente documental en donde se describió el proceso de construcción de la estructura territorial de México con base en las carreteras y no ya en la del ferrocarril.

Las tres secciones elegidas de la revista MAPA eran representativas de la diversidad de México y de las opciones paisajísticas entre los lectores. En el apartado de los "Caminos" se señaló el aumento de la inversión en las infraestructuras en el cardenismo, como las carreteras, que incrementaron la construcción del kilometraje. A la vez que se convirtieron en las rutas que estimulaban las nuevas relaciones con lo nacional a partir de la difusión y uso del automóvil, una tecnología que cambiaba la existencia humana y que en México modificaba las tradicionales formas del viaje. Las rutas históricas del ferrocarril desde la capital mexicana, por ejemplo, mantuvieron su atractivo para la revista al señalar, por ejemplo, el olor de los paisajes a vainilla rumbo al puerto de Veracruz, la ruta escénica de Guadalajara a Mazatlán y de ahí al puerto de Guaymas, Sonora o el trayecto más largo de la Ciudad de México a Ciudad Juárez.

La sección de "Automovilismo" era una plataforma abierta a la novedad de la movilidad y la motorización en los años treinta. La organización de clubes, como la Asociación Mexicana Automovilística (AMA) y diferentes filiales regionales, jugaron un papel esencial en la promoción de la velocidad y la autonomía del viaje que brindaba, a las clases medias, la independencia para acceder a una enseñanza basada en la variedad de los contenidos culturales e históricos del paisaje mexicano de forma agradable. Tal visión contrastaba con el marco eductativo estatal, regido por ideales socialistas, sin injerencia religiosa y técnicamente orientado a los sectores mineros, agrícolas e industriales. El aprendizaje, por parte de la revista MAPA, situaba el coche como una 
tecnología de exploración que dio origen al cambio de la mentalidad a lo espacial, los lectores aprendieron a adoptar las distancias como el nuevo marco para fijar la duración de los viajes.

La sección de "Viajes y excursiones" integraba la labor de las dos anteriores. MAPA impulsó una visión pedagógica del paisaje entre la clase media urbana instruida. Acapulco era el lugar preferido, a partir de la apertura de la carretera en 1928. En tan solo dos años, entre 1934 y 1936, el lector vivió la compresión del espacio, de pasar 12 horas al volante del coche para cumplir los 450 kilómetros, la distancia entre la capital mexicana con este puerto del Pacífico, a tan solo 80 minutos en un vuelo comercial de la empresa Aeronaves de México. Eran tiempos de cambio y la revista se situaba en el centro al decir qué ver, a través de un foto reportaje, donde se informaba a los lectores de esta atrevida práctica cultural, llena de extrañeza, de miedos y de experiencias vividas con el cambio a una observación oblicua del paisaje. Aún con esta facilidad, los paisajes marítimos perduraban en la memoria como espacios desconocidos y temidos por el calor y las enfermedades como el paludismo. Ahí se alentaba a los lectores de la revista MAPA a viajar para familiarizarse al mirarlos directamente y convertirlos en espacios vividos. La sugerencia abarcaba, además, a Mazatlán por el lado del Pacífico y a los puertos de Veracruz y Tampico en el Golfo de México. Zihuatanejo era un sitio excepcional en la geografía del Pacífico que fascinaba al viajero por la intensa experiencia tanto por el aislamiento del mundo moderno, como por el traslado a un paisaje con aspecto de remotos orígenes, aunque su acceso en barco desde Acapulco era limitado.

En las ediciones, entre 1934 y 1936, se presentaron paisajes que combinaban lo bello y lo sublime, como los de Morelia, Querétaro, Guanajuato y Guadalajara, se añadieron los de Puebla y, como paisajes rurales, las Huastecas y el Istmo de Tehuantepec, desde el corredor entre Coatzacoalcos y Minatitlán. A partir de 1937, la revista dio un giro a la forma de considerar lo espacial del viaje a partir de las distancias, primero, a los paisajes más cercanos de la capital mexicana, como el Desierto de los Leones y otros lugares dentro del Valle de México. Luego se presentaron excursiones a mayor distancia: Cuernavaca, Taxco, Tlaxcala, Pachuca, Cuautla, Jacala y Cacahuamilpa. En seguida los lugares alejados: Jalapa, Mazatlán, Mérida, Orizaba, Pátzcuaro, Monterrey, Guadalajara, Acapulco, Oaxaca y Alvarado. Se ha constatado, por lo anterior, que desde la Ciudad de México se abrió un canal de comunicación a través de la revista MAPA que transformaba la mirada de los viajeros ante la mayor variedad de rasgos naturales y humanos registrados, en este sentido, la edición respaldaba la construcción de los paisajes mexicanos.

\section{Referencias bibliográficas}

AIME, M. Cultura. Buenos Aires: Adriana Hidalgo editora, 2015.

ALBIÑANA, S. México ilustrado 1920-1950. México: Conaculta-Editorial RM, 2014.

ARRIOLA, D. Postcards from the Rio Bravo border. Picturing the place, placing the picture, 1900s 1950s. Austin: University of Texas Press, 2013.

BERGER, D. The Development of Mexico's Tourism Industry, Pyramids by Day, Martinis by Night. New York: Palgrave, 2006. 
BERQUE, A. El pensamiento paisajero. Madrid: Biblioteca Nueva, 2009.

BOOTH, R. Turismo y representación del paisaje. La invención del sur de Chile en la mirada de la Guía del Veraneante (1932-1962). Nuevo Mundo. Mundos Nuevos. Débats. 2008. Disponible en internet: http://nuevomundo.revues.org/index25052.html

BOARDMAN, A. Destination Mexico. U. S. Tourism to Mexico, 1880s - 1950s. Dallas: DeGolyer Library - Southern Methodist University, 2001.

CATALÀ P. Fotografía, arte y publicidad. Madrid: Casimiro libros, 2005.

CLAVAL, P. La Geografía cultural. Buenos Aires: Eudeba, 1999.

CLAVAL, P. El enfoque cultural y las concepciones geográficas del espacio. Boletín de la Asociación de Geógrafos Españoles, 2002, №34, p. 21-39.

COSGROVE, D. Observando la naturaleza: el paisaje y el sentido europeo de la vista. Boletín de la Asociación de Geógrafos Españoles, 2002, №34, p. 63-89.

COSGROVE, D. \& DANIELS, S. The Iconography of Landscape. Essays on the symbolic representation, design, and use of past environments. Cambridge: Cambridge University Press, 1988.

DEPARTAMENTO DE TURISMO. Down to Mexico in your own car. México: Secretaría de Gobernación, 1936.

DOMINGUES, A. A Paisagem revisitada. Finisterra, 2001, Vol. XXXVI, Nº 72, p. 55-66.

DOROTINSKY, D. Revistas mexicanas ilustradas 1920-1960. Alquimia. Sistema Nacional de Fototecas, $2008, \mathrm{~N}^{\circ} 33$, p. 7-10.

EDENSOR, T. Automobility and National Identity. Representation, Geography and Driving Practice. Theory, Culture \& Society. 2004, Vol. 21, N 4-5, p. 101-120.

ERRÁZURIZ, T. Ocio, placer y (auto)movilidad en la construcción simbólica de los "alrededores de Santiago". EURE, 2016, Vol. 42, Nº127, p. 279-305.

FERNÁNDEZ, F. Geografía cultural. En: HIERNAUX, D. y LINDÓN, A. Tratado de Geografía Humana. Barcelona: Anthropos-UAM-Iztapalapa, 2006, p. 220-253.

FREEMAN, J.B. Transnational Mechanics: automobility in México, 1895-1950. New York: The City University of New York, 2012a.

FREEMAN, J.B. El automóvil y el turismo norteamericano en México, 1900-1940. En: ÁLVAREZ PALMA, I.A.S.; PICHARDO ARELLANO, G. y SALAZAR VELÁZQUEZ, C. Ciencia y tecnología. Apuntes para su reflexión en la historia de México. México: Sociedad Mexicana de Historia de la Ciencia y la Tecnología, 2012b, p. 81-92. 
GARCÍA, J.; PUENTE, P. y TRILLO, J. La imagen de España en National Geographic Magazine (18881936). Scripta Nova, Revista Electrónica de Geografia y Ciencias Sociales, 2013, Vol. XVII, N 454, p. 1-40.

GIUCCI, G. La vida cultural del automóvil. Rutas de la modernidad cinética. Buenos Aires: Universidad Nacional de Quilmes/Prometeo, 2007.

GONZÁLEZ, L. Historia de la Revolución Mexicana, 1934-1940. Los días del presidente Cárdenas. México: El Colegio de México, tomo 15, 1981.

GONZÁLEZ, O. Construcción de carreteras y ordenamiento del territorio. Revista Mexicana de Sociología, 1990, N³, p. 49-67.

GONZÁLEZ, J.A. Geografía del desierto y turismo de la naturaleza. La revista En Viaje y la mirada sobre el paisaje nortino: 1945-1961. Revista de Geografía Norte Grande, 2013, № 54, p. 219-239.

HARBER, S. H. Industria y subdesarrollo. La industrialización de México, 1890-1940. México: Alianza Editorial, 1992.

HERNÁNDEZ, J.M. Ser-paisaje. Madrid: Abada Editores, 2016.

JOLLY, J. Pátzcuaro desde lo alto: muralismo, turismo, y el estado mexicano en Michoacán. En: OROZCO, L. 3er. Encuentro Internacional de Pintura Mural. Muros frente a muros, creación, investigación, restauración. Toluca: Universidad Autónoma del Estado de México, 2014, p. 82-93.

LEIDENBERGER, G. Tres revistas mexicanas de arquitectura. Portavoces de la modernidad, 19231950. Anales del Instituto de Investigaciones Estéticas, 2012, Vol. XXXIV, № 101, p. 109-138.

LIBRO AZUL DE MÉXICO. State of Veracruz - Facts about Mexico - The Country of the Future - The Blue Book of Mexico. México: Compañía Editorial Pan-Americana, 1923.

LOAEZA, S. Clases medias y política en México. México: El Colegio de México, 2012.

LÓPEZ, R.A. Crafting Mexico. Intellectuals, Artisans, and the State after the Revolution. Durham \& London: Duke University Press, 2010.

MADERUELO, J. Paisaje y pensamiento. Madrid: Abada editores, 2006.

MADERUELO, J. Paisaje e historia. Madrid: Abada editores, 2009.

MAPA, Revista de Turismo. México: Editorial Mercurio, 1934-1940.

MARTÍNEZ DE PISÓN, E. Miradas sobre el paisaje. Madrid: Biblioteca Nueva, 2009.

MINCA, C. El sujeto, el paisaje, y el juego posmoderno. En: Nogué, J. (editor). El paisaje en la cultura contemporánea. Madrid: Biblioteca Nueva, 2008, p. 209-231. 
MITCHELL, B.R. International Historical Statistics. The Americas 1750-2005. New York: Palgrave Macmillan, Sixth edition, 2007.

MONSIVÁIS, C. Notas sobre la cultura mexicana en el siglo XX. Historia general de México. Tomo 2. México: El Colegio de México - Harla, 1988, p. 1375-1548.

MRAZ, J. Today, Tomorrow, and Always. The Golden Age of Illustrated Magazines in Mexico, 19371960. In: JOSEPH, G.; RUBENSTEIN, A. \& ZOLOV, E. Fragments of a Golden Age. The Politics of Culture in Mexico Since 1940. Durham: Duke University Press, 2001, p. 116-157.

NOGUÉ, J. El paisaje en la cultura contemporánea. Madrid: Biblioteca Nueva, 2008.

ORTEGA, N. Entre explicación y comprensión: El concepto de paisaje en la geografía moderna. En: MADERUELO, J. (editor). Paisaje y pensamiento. Madrid: Abada Editores, 2006, p. 107-129.

PIGLIA, M. Autos, rutas y turismo, el automóvil club argentino y el estado. Buenos Aires: Siglo veintiuno editores, 2014.

ROMERO, J.L. Estudio de la mentalidad burguesa. México: Alianza editorial, 1989.

QUINTANA, I. Producción cultural. En: SZURMUK, M. y MCKEE I.R. (coordinadores). Diccionario de Estudios Culturales Latinoamericanos. México: Instituto Mora y siglo veintiuno editores, 2009, p. 239-244.

SALTER, CH.L. Cultural Geography as Discovery. In: FOOTE, K.E.; HUGILL, P.J. MATHEWSON, K. \& SMITH, J.M. Re-Reading Cultural Geography. Austin: University of Texas Press, 1994, p. 429-436.

SECRETARÍA DE COMUNICACIONES Y OBRAS PÚBLICAS. Memoria sobre el camino México-Nuevo Laredo, México: Dirección Nacional de Caminos, 1936.

SECRETARÍA DE COMUNICACIONES Y OBRAS PÚBLICAS. Memoria del camino nacional México-Morelia-Guadalajara, México: Dirección Nacional de Caminos, 1939.

SHAFFER, M.S. See American First. Tourism and National Identity, 1880-1940. Washington, D.C.: Smithsonian Books, 2001.

SILVA, P. Un lugar para exhibir, clasificar y coleccionar: la revista ilustrada como una galería de progreso. En: GONZÁLEZ, B. y ANDERMANN, J. (editores). Galerías del progreso. Museos, exposiciones y cultura visual en América Latina. Rosario: Beatriz Viterbo Editora, 2006, p. 373-406.

SILVESTRI, G. El lugar común. Una historia de las figuras del paisaje en el Río de la Plata. Buenos Aires: edhasa, 2011.

TESSER, C. Algunas reflexiones sobre los significados del paisaje para la Geografía. Revista de Geografía Norte Grande, 2000, № 27, p. 19-26. 
URIBE, M.N. La Compañía México Fotográfico y la promoción del turismo a finales de los años veintes. México: UNAM, Facultad de Filosofía y Letras, tesis de maestría en Historia del Arte, 2011.

ZUSMAN, P. La Revista Geográfica Americana en la década de 1930: entre el modelo de la National Geographic y la invención de los paisajes argentinos orientados a la práctica turística. Revista Registros, 2012, Nº 9, p. 81-96. 